\title{
Determinants of inspiratory muscle strength in healthy humans
}

\section{Authors:}

Peter I. Brown ${ }^{\mathrm{a}}$, Michael A. Johnson ${ }^{\mathrm{b}}$ and Graham R. Sharpe ${ }^{\mathrm{b}}$

\author{
Affiliation: \\ ${ }^{a}$ English Institute of Sport, Loughborough, UK \\ ${ }^{\mathrm{b}}$ School of Science and Technology, Nottingham Trent University, Nottingham, UK
}

\section{Running Title:}

Inspiratory muscle strength

\section{Acknowledgements:}

None

\section{Corresponding author:}

Dr. Peter I. Brown

English Institute of Sport, Loughborough University, LE11 3TU, UK

email:peter.brown@eis2win.co.uk, fax:+44 (0)1509 217535, telephone:+44 (0)7860 783007 


\section{ABSTRACT}

We investigated 1) the relationship between the baseline and inspiratory muscle training (IMT) induced increase in maximal inspiratory pressure $\left(P_{\mathrm{I}, \max }\right)$ and 2$)$ the relative contributions of the inspiratory chest wall muscles and the diaphragm $\left(P_{\mathrm{oes}} / P_{\mathrm{di}}\right)$ to $P_{\mathrm{I}, \mathrm{max}}$ prior to and following-IMT. Experiment 1: $P_{\mathrm{I}, \max }$ was assessed during a Müeller manoeuvre before and after 4-wk IMT $(\mathrm{n}=30)$. Experiment 2: $P_{\mathrm{I}, \max }$ and the relative contribution of the inspiratory chest wall muscles to the diaphragm $\left(P_{\mathrm{oes}} / P_{\mathrm{di}}\right)$ were assessed during a Müeller manoeuvre before and after 4-wk IMT (n=20). Experiment 1: $P_{\mathrm{I}, \max }$ increased $19 \%(P<0.01)$ post-IMT and was correlated with baseline $P_{\mathrm{I}, \max }(r=-0.373, P<0.05)$. Experiment 2: baseline $P_{\mathrm{I}, \max }$ was correlated with $P_{\mathrm{oe}} / P_{\mathrm{di}}(r=0.582, P<0.05)$ and after IMT $P_{\mathrm{I}, \text { max }}$ increased $22 \%$ and $P_{\mathrm{oe}} / P_{\mathrm{di}}$ increased 5\% $(P<0.05)$. In conclusion, baseline $P_{\mathrm{I}, \max }$ and the contribution of the chest wall inspiratory muscles relative to the diaphragm affect, in part, baseline and IMT-induced $\Delta P_{\mathrm{I}, \max }$. Great care should be taken when designing future IMT studies to ensure parity in the between-subject baseline $P_{\mathrm{I}, \max }$.

Key words: Respiratory muscles, inspiratory muscle training, diaphragm, chest wall 


\subsection{Introduction}

The maximal inspiratory pressure $\left(P_{\mathrm{I}, \mathrm{max}}\right)$ generated during a Müeller manoeuvre reflects the volitional force output of the inspiratory muscles working in synergy and is an established and reliable measure of global inspiratory muscle strength in health (e.g., Romer and McConnell, 2004) and disease (e.g., Larson et al., 1993). Inspiratory muscle training (IMT) specifically targets and progressively overloads these muscles and the resulting change in $P_{\mathrm{I}, \max }$ may reflect morphological adaptation of these muscles (Downey et al., 2007) and/or changes in inspiratory muscle recruitment patterns. $P_{\mathrm{I}, \max }$ is frequently reported as an outcome measure used to quantify the efficacy of such interventions (Brown et al., 2012).

The between-participant improvements in $P_{\mathrm{I}, \max }$ following IMT is highly variable ranging from $\sim 10 \%$ up to $~ 55 \%$ (Brown et al., 2012; Leith and Bradley, 1976; Romer et al., 2002b; Volianitis et al., 2001b). It has been postulated that the baseline (i.e. resting and untrained) $P_{\mathrm{I}, \max }$ may explain, in part, the variability in the relative increase in $P_{\mathrm{I}, \max }$ following IMT (Johnson et al., 2007) as the window for physiological adaptation is reduced in participants with a greater baseline strength (Kraemer et al., 1996). This notion has gained support from studies demonstrating a negative relationship between the baseline and $\Delta P_{\mathrm{I}, \max }$ following IMT in healthy and clinical populations (Brown et al., 2008; Winkler et al., 2000). Therefore, understanding this relationship may be important when designing IMT-based interventions in order to maximise confidence in the outcomes of the intervention. However, this hypothesis has yet to be systematically addressed using individuals with a wide range of baseline $P_{\mathrm{I}, \max }$ values and a range of outcome measures. Therefore, the first aim of this study was to investigate the relationship between baseline $P_{\mathrm{I}, \max }$ and the changes in $P_{\mathrm{I}, \max }$ and a wide range of outcome measures including inspiratory muscle endurance and dynamic inspiratory muscle function following a period of IMT (Experiment 1). These data aim to provide important 
methodological guidelines for participant recruitment for future IMT based intervention studies which have the potential to influence a large number of research trials (c.f., Illi et al., 2013).

In addition to the between-participant variability in $\Delta P_{\mathrm{I}, \mathrm{max}}$ following IMT, baseline measures of inspiratory muscle strength are also highly variable between individuals. For example, in motivated, healthy participants fully familiarised with the Müeller manoeuvre and using the same predictive equation (Wilson et al., 1984), some studies report $P_{\mathrm{I}, \max }$ values $\sim 137 \%$ of predicted (Johnson et al., 2007) while others, despite the same sex and similar age are considerably lower $\sim 90 \%$ of predicted (Romer et al., 2002a). The mechanism(s) explaining this phenomenon are unknown but may be accounted for by the degree of relative activation of the diaphragm and the accessory chest wall inspiratory muscles during inspiratory efforts (Hershenson et al., 1989). During maximal inspiratory efforts at greater muscles lengths, the weakest inspiratory muscles (i.e., the chest wall muscles) are maximally activated and the strongest inspiratory muscle (the diaphragm) is sub-maximally activated (Hershenson et al., 1988; Nava et al., 1993). However, despite the markedly different intrathoracic pressures generated and activation patterns, the relative strengths of these muscles must be equal. If the neural activation of the diaphragm was maximal during these efforts, the thoracoabdominal configuration would be distorted, thereby reducing respiratory system compliance (Kenyon et al., 1997) and increasing the potential for shearing injuries (Hershenson et al., 1988). Consequently, increasing the strength of the weaker chest wall inspiratory muscles through targeted training should increase their neural activation and maximal force generating capacity, resulting in greater activation of the diaphragm and thus increased $P_{\mathrm{I}, \max }$ (Hershenson et al., 1988). Therefore, the second aim of this study was to evaluate the relationship between the relative contributions of the chest wall inspiratory muscles and the 
diaphragm to global inspiratory muscle strength before and after IMT (Experiment 2) in attempt to explain the variability in $P_{\mathrm{I}, \max }$ at baseline and following specific training. 


\subsection{Materials and methods}

\subsection{Participants}

Following ethics approval and written informed consent, 50 non-smoking, recreationally active individuals volunteered for this study. Participants abstained from alcohol, caffeine and exercise in the $24 \mathrm{~h}$ prior to testing and arrived at the laboratory $2 \mathrm{~h}$ post-prandial. All laboratory visits were separated by at least $48 \mathrm{~h}$ and performed at a similar time of day.

\subsection{Experiment 1}

Participants $(\mathrm{n}=30$; age $22.8 \pm 6.6$ years, body mass $69.9 \pm 12.0 \mathrm{~kg}$, stature $1.72 \pm 0.07 \mathrm{~m})$ were initially familiarised with all testing procedures and subsequently attended the laboratory on two occasions prior to and following a $4 \mathrm{wk}$ control period and then following a 4 wk IMT period; in total visiting the laboratory on 9 occasions (of which two were for inspiratory muscle strength measurements during the intervention periods; see Intervention, below). In this repeated measures design, the post-control data served as the pre-IMT baseline data. During the first visit, participants completed pulmonary and maximal inspiratory muscle function tests. In the second visit maximal dynamic inspiratory muscle function and inspiratory muscle endurance were assessed.

\subsection{Visit 1: pulmonary and maximal inspiratory muscle function}

Pulmonary function was assessed in accordance with published guidelines (ATS/ERS, 2005) using a pneumotachograph (ZAN 600USB, Nspire Health, Oberthulba, Germany). The pneumotachograph was calibrated prior to all trials with a $3 \mathrm{~L}$ syringe according to the manufacturer guidelines. $P_{\mathrm{I}, \max }$ was measured as an index of global inspiratory muscle strength using a hand-held mouth pressure meter fitted with a flanged mouthpiece 
(MicroRPM, Micro Medical, Kent, UK) calibrated over the physiological range using a digital pressure meter (Pirani strain gauge, MKS Barathon, MKS Instruments, MA, USA). The mouthpiece assembly incorporated a $1 \mathrm{~mm}$ orifice to prevent glottic closure and minimise the contribution of the buccal muscles during inspiratory efforts. Manoeuvres were performed standing, initiated from residual volume (RV), and sustained for at least $1 \mathrm{~s}$. A minimum of 3 and maximum of 8 manoeuvres were performed every $30 \mathrm{~s}$, and the maximum value of 3 measures that varied by $<5 \%$ was used for subsequent analysis (ATS/ERS, 2002). In addition, the $P_{\mathrm{I}, \mathrm{max}}$ data was also combined with that of our previous studies for further analyses (Brown et al., 2008, 2010, 2012; Johnson et al., 2007) which was collected using identical equipment and the procedures stated above.

\subsection{Visit 2: Dynamic inspiratory muscle function and inspiratory muscle endurance}

Maximal dynamic inspiratory muscle function was assessed to determine the pressure-flow relationship of the inspiratory muscles using a pressure threshold arrangement (POWERbreathe ${ }^{\circledR}, \mathrm{HaB}$ Ltd, UK) as described previously (Romer and McConnell, 2004). Inspiratory mouth pressure was measured by a differential pressure transducer $( \pm 400$ $\mathrm{cmH}_{2} \mathrm{O}$; TSD104A, BIOPAC systems Inc., California, USA), calibrated over the physiological range (Pirani strain gauge, MKS Barathon, MKS Instruments, MA, USA), inserted in to the ceiling of the device. Inspiratory airflow was measured using a calibrated pneumotachograph (TSD160A Fleisch number 3 Pneumotachograph, BIOPAC systems Inc., California, USA) connected distally to the inspiratory port of the device. The pressure and flow signals were digitised at $200 \mathrm{~Hz}$ and recorded using bespoke software (Acqknowledge version 3.7.3, BIOPAC systems Inc., California, USA). Inspiratory pressure at zero flow $\left(P_{0}\right)$ was measured by closing the inspiratory port of the device and exposing a $1 \mathrm{~mm}$ leak to prevent glottic closure. Participants performed in random order 3 maximal inspiratory efforts 
from $\mathrm{RV}$ at $\sim 0,20,25,35,50$ and $65 \% P_{0}$ separated by $30 \mathrm{~s}$. The product of inspiratory pressure $\left(P_{\mathrm{I}}\right)$ and flow $\left(\dot{\mathrm{V}}_{\mathrm{I}}\right)$ at each $\% P_{0}$ defined inspiratory muscle power $\left(\dot{\mathrm{W}}_{\mathrm{I}}\right)$. Maximal inspiratory flow $\left(\dot{\mathrm{V}}_{\mathrm{I}} \max \right)$ and power $\left(\dot{\mathrm{W}}_{\mathrm{I}} \max \right)$ were calculated from extrapolation of the linear pressure-flow relationship and identification of the asymptote of the power-flow relationship, respectively. Optimal flow $\left(\dot{\mathrm{V}}_{\mathrm{opt}}, \mathrm{L} \cdot \mathrm{s}^{-1}\right.$ and $\left.\% \dot{\mathrm{V}}_{\mathrm{I}} \mathrm{max}\right)$ and optimal pressure ( $\dot{P}_{\text {opt }}, \mathrm{cmH}_{2} \mathrm{O}$ and $\% P_{0}$ ) were subsequently calculated. The maximal rate of inspiratory pressure development (MRPD) was assessed during inspiratory efforts at $P_{0}$ and was defined as the positive peak of the pressure derivative as a function of time.

Incremental threshold loading (ITL) assessed inspiratory muscle endurance using a weighted plunger inspiratory pressure threshold device as described previously (Johnson et al., 1996, 1997). The initial threshold pressure was $10 \mathrm{cmH}_{2} \mathrm{O}$ and increased by $5 \mathrm{cmH}_{2} \mathrm{O} \cdot \mathrm{min}^{-1}$ until task failure. Task failure (endurance time) was defined as the inability to maintain tidal volume or the target pressure for three consecutive breaths despite verbal encouragement (ATS/ERS, 2002). Participants performed the test seated and were required to maintain tidal volume at resting levels while breathing frequency and duty cycle were paced by an audio metronome (breathing frequency $=15$ breaths $\cdot \min ^{-1}$, duty cycle $\left.=0.5\right)($ Johnson et al., 1997). Online integration of inspiratory flow measured using a calibrated Fleisch number 3 pneumotachograph (TSD160A, BIOPAC systems Inc., California, USA) attached to the inspiratory port of the device provided continual visual feedback of the target tidal volume. Inspiratory mouth pressure was measured using a differential pressure transducer $( \pm 400$ $\mathrm{cmH}_{2} \mathrm{O}$; TSD104A, BIOPAC systems Inc., California, USA), calibrated over the physiological range, inserted into the ceiling of the device. 


\subsection{Intervention}

Throughout the 4 wk control period participants performed no IMT. During the 4 wk intervention period 30 consecutive maximal dynamic inspiratory efforts were performed twice daily over a 4 wk period using a pressure-threshold device (POWERbreathe ${ }^{\circledR}, \mathrm{HaB}$ Ltd, UK) with a training load of $50 \% P_{\mathrm{I}, \max }$. This protocol is known to be effective in eliciting an adaptive response (Brown et al., 2008, 2010, 2012). Each inspiratory effort was initiated from RV and participants strove to maximise tidal volume such that task failure was reached at around the $30^{\text {th }}$ inspiratory effort. Measurement of $P_{\mathrm{I}, \max }$ following 2 wk of the intervention period permitted the resistance of the device to be adjusted to ensure the appropriate relative training load. Participants were instructed to record IMT adherence in a training diary. Postintervention trials were conducted at least $48 \mathrm{~h}$ following the cessation of the intervention period.

\subsection{Experiment 2}

Participants were initially familiarized with all testing procedures, divided into a control $(n=10 ;$ age $27.0 \pm 4.5$ years, body mass $75.0 \pm 8.2 \mathrm{~kg}$, stature $1.80 \pm 0.08 \mathrm{~m})$ or an IMT group $(\mathrm{n}=10$; age $21.3 \pm 2.9$ years, body mass $72.4 \pm 10.1 \mathrm{~kg}$, stature $1.76 \pm 0.06 \mathrm{~m})$ and completed pulmonary and inspiratory muscle function tests (for protocol see visit 1: Experiment 1). Subsequently, prior to and following a 4 wk control period (no IMT) or a 4 wk IMT intervention (see Intervention, Experiment 1), $P_{\mathrm{I}, \max }$, oesophageal $\left(P_{\mathrm{oe}}\right)$, gastric $\left(P_{\mathrm{ga}}\right)$ and the transdiaphragmatic pressure $\left(P_{\mathrm{di}}\right)$ were assessed during repeated Müeller manoeuvres. Volitional manoeuvres were favoured above non-volitional techniques due to their superior between-day (i.e., pre to post intervention) reliability (Hart et al., 2001; Romer and McConnell, 2004). Every 30 s, 8 efforts were performed from RV and following a 5 min break from functional residual capacity (FRC) in order to minimise the effects of the elastic 
recoil pressure of the lung and chest wall upon $P_{\mathrm{I}, \max }$ (ATS/ERS, 2002). During efforts from FRC an end-expiratory $P_{\mathrm{oe}}$ of approximately -2.0 to $-5.0 \mathrm{cmH}_{2} \mathrm{O}$ ensured a constant endexpiratory lung volume (Romer et al., 2007). All efforts were performed while standing to minimise the compressive effects of the mediastinal compartment on $P_{\text {oe }}$ (Baydur et al., 1982) and efforts were performed against a calibrated mouth pressure meter. The device was fitted with a flanged mouthpiece (MicroRPM, Micro Medical, Kent, UK) aligned at the mouth using a table-mounted clamp. Data were obtained from the maximum $P_{\mathrm{di}}$ of 3 measures that varied by $<5 \%$ (ATS/ERS, 2002).

\subsection{Intrathoracic pressure measurements}

$P_{\mathrm{oe}}$ and $P_{\mathrm{ga}}$ were measured via two latex nasopharyngeal balloons sealed over a single catheter (Milic-Emili et al., 1964) (Nspire health, Oberthulba, Germany). The oesophageal and gastric balloons were passed in to the stomach and filled with 1 and $2 \mathrm{ml}$ of air, respectively, according to their optimal pressure-volume characteristics. The oesophageal balloon was withdrawn until a negative pressure deflection was observed during inspiration and then withdrawn a further $10 \mathrm{~cm}$ to ensure correct placement within the oesophagus; positioning was confirmed using the occlusion technique (Baydur et al., 1982). Participants were instrumented with the same catheter during their experimental trials and the internal length of the catheter passed in to the participant was recorded on the first trial and repeated in all subsequent trials. Each catheter was connected to a differential pressure transducer $( \pm$ $400 \mathrm{cmH}_{2} \mathrm{O}$; TSD104A, BIOPAC systems Inc., California, USA) calibrated across the physiological range using a digital pressure meter (Pirani strain gauge, MKS Barathon, MKS Instruments, MA, USA). The pressure signal was digitised at $200 \mathrm{~Hz}$ and recorded using bespoke software (Acqknowledge version 3.7.3, BIOPAC systems Inc., California, USA). $P_{\mathrm{di}}$ 
was calculated by online subtraction of $P_{\mathrm{oe}}$ from $P_{\mathrm{ga}}$. The pattern of relative chest wall muscle recruitment was expressed by the $P_{\mathrm{oe}} / P_{\mathrm{di}}$ ratio (Nava et al., 1993).

\subsection{Statistical analyses}

Differences between variables were assessed using a paired or independent samples $t$-test. Pearson's product moment correlation assessed the relationships between selected variables. Statistical significance was set a-priori at $P \leq 0.05$. Data are presented as mean \pm SD unless stated otherwise. 


\subsection{Results}

\subsection{Experiment 1}

Pulmonary, static and dynamic inspiratory muscle function and inspiratory muscle endurance prior to and following the control and intervention periods are shown in Table 1. One participant failed to complete the post-IMT measures and their data were omitted from the analyses. All variables were unchanged following the control period. Baseline median $P_{\mathrm{I}, \max }$ (\% predicted: according to the equation of Wilson et al., 1984) was $156 \mathrm{cmH}_{2} \mathrm{O}(147 \%)$ and ranged from $82(66 \%)$ to $278 \mathrm{cmH}_{2} \mathrm{O}(227 \%)$. Throughout the intervention, IMT compliance was $87 \pm 11 \%$ which is similar to previous training studies (Illi et al., 2013). $P_{\mathrm{I}, \mathrm{max}}$ increased $19 \pm 10 \%$ following the intervention $(P<0.001$, range 6 to $45 \%)$ and was negatively correlated with the baseline $P_{\mathrm{I}, \max }(\mathrm{n}=29 ; r=-0.373, P<0.05$ : medium effect; Figure 1A). When results were combined with data previously collected within our laboratory the relationship improved further $(\mathrm{n}=67 ; r=-0.48, P<0.01$ : large effect; Figure 1B). Pulmonary function remained unchanged following IMT and as expected, with the exception of $\% \dot{\mathrm{V}}_{\mathrm{I}} \max$ and $\% P_{0}$, all measures of dynamic inspiratory muscle function were improved $\left(P<0.05\right.$; Table 1). Baseline $P_{\mathrm{I}, \max }$ was negatively correlated with the relative increase in $\dot{\mathrm{W}}_{\mathrm{I}} \max (r=-0.458, P<0.05)$ and $\dot{\mathrm{V}}_{\mathrm{I}} \max (r=-0.383, P<0.05)$. Inspiratory muscle endurance increased by $27 \%$ following IMT $(P<0.05)$.

\subsection{Experiment 2}

Baseline $P_{\mathrm{I}, \max }$ at RV and FRC and pulmonary function for the control and IMT groups are shown in Table 2. Two participants from the IMT group failed to complete the postintervention trials and their data were omitted from the analyses. All variables were unchanged following the intervention period in the control group. Throughout the intervention, IMT compliance was $92 \pm 9 \% . P_{\mathrm{I}, \max }$ increased in the IMT group $22 \pm 24 \%$ at 
$\mathrm{RV}$ (pre: $170 \pm 50 \mathrm{cmH}_{2} \mathrm{O}$ vs. post: $\left.196 \pm 55 \mathrm{cmH}_{2} \mathrm{O} ; P<0.05\right)$ and $20 \pm 21 \%$ at FRC (pre: $137 \pm 30$ vs. post: $156 \pm 24 ; P<0.05)$. Intrathoracic pressures at RV and FRC for both groups prior to and following the intervention period are shown in Table 3. Following IMT, $P_{\mathrm{oe}}$ decreased (i.e. became more negative) (RV: $14 \pm 11 \%$, FRC: $18 \pm 13 \%$; $P<0.01$ ), whereas increases were observed in $P_{\mathrm{di}}(\mathrm{RV}: 9 \pm 9 \%$, FRC: $15 \pm 14 \% ; P<0.05)$ and $P_{\mathrm{oe}} / P_{\mathrm{di}}(\mathrm{RV}: 5 \pm$ $5 \%, \mathrm{RV} 3 \pm 3 \% ; P<0.05)$.

Pooled baseline $P_{\mathrm{I}, \mathrm{max}}$ was positively correlated with pooled baseline $P_{\mathrm{oe}} / P_{\mathrm{di}}$ at RV $(r=0.582$, $P<0.05)$ and FRC $(r=0.523, P<0.05)$. Pooled baseline $P_{\mathrm{I}, \max }$ was also correlated with $P_{\mathrm{di}}$ at both RV $(r=0.561, P<0.05)$ and FRC $(r=0.515, P<0.05)$. Following IMT the absolute $(r=$ 0.707, $P<0.05)$ and relative $(r=0.759, P<0.05)$ increase in $P_{\mathrm{di}}$ was correlated with the absolute increase in $P_{\mathrm{oe}}$ at RV. No relationship was observed however between $\% \Delta P_{\mathrm{I} \text {,max }}$ and $\Delta P_{\mathrm{oe}} / P_{\mathrm{di}}$ following IMT at RV $(r=0.16, P>0.05)$ and FRC $(r=-0.25, P>0.05)$. 


\section{Discussion}

\subsection{Main findings}

The aim of this study was to investigate the determinants of $P_{\mathrm{I}, \mathrm{max}}$ before and after IMT. In Experiment 1, baseline $P_{\mathrm{I}, \max }$ was negatively correlated with IMT-mediated increases in $P_{\mathrm{I}, \max }, \quad \dot{\mathrm{W}}_{\mathrm{I}} \max$ and $\dot{\mathrm{V}}_{\mathrm{I}} \max$. In Experiment 2 , although baseline $P_{\mathrm{I}, \max }$ was positively correlated with $P_{\mathrm{oe}} / P_{\mathrm{di}}$ and $P \mathrm{di}$, IMT-mediated increases in these measures were not correlated.

\subsection{Experiment 1}

The negative relationship observed between baseline $P_{\mathrm{I}, \mathrm{max}}$ and the IMT-mediated increase in $P_{\mathrm{I}, \max }\left(\right.$ Figures $1 \mathrm{~A}$ and 1B) suggests that care must be taken to ensure parity in baseline $P_{\mathrm{I}, \mathrm{max}}$ between participants/experimental groups when designing IMT-based interventions. We have identified for the first time that the baseline strength of these muscles may affect the efficacy (when based on $P_{\mathrm{I}, \max }$ ) of the IMT intervention. This relationship confirms and extends the suggestions of previous studies in healthy (Brown et al., 2008) and clinical (Winkler et al., 2000) populations and may explain the differentiated IMT-induced increase in $P_{\mathrm{I}, \mathrm{max}}$ observed in previous studies (range: 10\% to 55\%) (Brown et al., 2008, 2010, 2012; Leith and Bradley, 1976; Romer et al., 2002b; Volianitis et al., 2001b). The large range of $\% \Delta P_{\mathrm{I}, \max }$ after IMT $(>45 \%)$ demonstrates the great plasticity of the inspiratory muscles and importantly, that these muscles behave similarly to other non-respiratory skeletal muscles during strength training. For example, in limb skeletal muscles the physiological potential for adaptation following strength training has been shown to be inversely related to the baseline strength; therefore, the closer the muscles are to their physiological ceiling, the smaller the potential for physiological adaptation (Häkkinen, 1994; Kraemer et al., 1996). However, since baseline $P_{\mathrm{I}, \max }$ explained $23 \%$ of the variance in $\% \Delta P_{\mathrm{I}, \max }$ (Figure $1 \mathrm{~B}$ ), other factors must also 
influence the inspiratory muscle training response and this presents an interesting avenue for future investigation.

Whilst the existence of a physiological ceiling may explain some of the $\% \Delta P_{\mathrm{I}, \max }, P_{\mathrm{I}, \max }$ is also prone to a learning effect (Volianitis et al., 2001a; Wen et al., 1997) probably because of the volitional, effort-dependent nature of the Müeller manoeuvre. Thus, as cautioned previously (Polkey et al., 2011) participants with lower baseline $P_{\mathrm{I}, \max }$ may also develop greater aptitude with the Müeller manoeuvre during IMT, which is technically very similar. Although inspiratory muscle recruitment patterns during IMT have not been examined, participants performing repeated inspiratory pressure-threshold loading tests adjust their breathing, and thus presumably inspiratory muscle recruitment, pattern in order to optimise inspiratory muscle endurance (Eastwood et al., 1998; Roussos et al., 1979). Therefore, some of the $\% \Delta P_{\mathrm{I}, \max }$ after IMT may also reflect a change in inspiratory muscle recruitment to "maximise" $P_{\mathrm{I}, \max }$, and this may occur to a greater extent in those with lower baseline $P_{\mathrm{I}, \max }$.

\subsection{Experiment 2}

Baseline $P_{\mathrm{I}, \max }$ was positively correlated with both $P_{\mathrm{di}}$ and $P_{\mathrm{oe}} / P_{\mathrm{di}}$ indicating that diaphragm and relative chest wall muscle recruitment are important determinants of $P_{\mathrm{I}, \mathrm{max}}$. Diaphragm and inspiratory intercostal muscle hypertrophy has been reported after IMT (Downey et al., 2007; Enright et al., 2006; Ramirez-Sarmiento et al., 2002) and such changes may have contributed to the IMT-mediated improvements in inspiratory muscle function observed in the present study. Furthermore, the increases in $P_{\mathrm{di}}$ (in the absence of a change in $P_{\mathrm{ga}}$ ) and $P_{\mathrm{oe}} / P_{\mathrm{di}}$ during the Müeller manoeuvre after IMT also indicates greater diaphragm activation and relative inspiratory chest wall muscle recruitment, respectively. Understanding the nature of these increases is, however, complicated due to the complex synergism between the 
diaphragm and the inspiratory intercostals during inspiration (De Troyer et al., 2005; Roussos et al., 1979). Specifically, voluntary activation of the diaphragm during a Müeller manoeuvre is dependent on lung volume, such that activation is lowest $(\sim 80 \%$, although inter-individual variability exists) at RV (McKenzie et al., 1996) and increases with increasing lung volume, with full activation being achieved at and above FRC (Gandevia et al., 1990; McKenzie et al., 1996). The submaximal activation of the diaphragm during a Müeller manoeuvre at RV may result from reflex inhibition of the phrenic motoneurones (McKenzie et al., 1996) and serve to minimise chest wall distortion (De Troyer et al., 2005). Given these observations, the increased $P_{\mathrm{di}}$ measured at RV after IMT in the present study may have been permitted because of greater chest wall muscle activation and subsequently less reflex inhibition of the phrenic motoneurones.

Reasons for the increased $P_{\mathrm{oe}} / P_{\mathrm{di}}$ after IMT remain somewhat less clear, as does the functional significance of this change given the absence of a relationship between $\% \Delta P_{\mathrm{oe}} / P_{\mathrm{di}}$ and $\% \Delta P_{\mathrm{I}, \max }$. The length-tension relationships of the diaphragm and inspiratory intercostals are not matched over the vital capacity range (De Troyer et al., 2005) and thus the relative loads placed on these muscles during IMT may differ. Indeed, McConnell et al. (2002) speculate that IMT imposes a greater relative training load on the inspiratory chest wall muscles compared to the diaphragm (McConnell et al., 2002), which might explain, in part, our observed increase in $P_{\mathrm{oe}} / P_{\mathrm{di}}$. However, this suggestion is based on there being submaximal diaphragm activation, and greater chest wall muscle recruitment, during a Müeller manoeuvre that evokes $P_{\mathrm{I}, \mathrm{max}}$, whereas it seems unlikely that such inhibition would be seen during IMT at $50 \% P_{\mathrm{I}, \mathrm{max}}$. Indeed, during submaximal inspiratory loading the diaphragm and inspiratory chest wall muscles undergo periodic recruitment and derecruitment, which may limit/delay fatigue of these muscles (Roussos et al., 1979). Thus, 
rather than IMT evoking preferential loading of inspiratory chest wall muscles, an alternative explanation is that repeated IMT simply enhanced the participants ability to recruit the inspiratory chest wall muscles during loaded inspiratory efforts. This notion could be examined in future studies using periodic measures of inspiratory muscle recruitment throughout an IMT intervention.

\subsection{Conclusions}

This study demonstrates that baseline $P_{\mathrm{I}, \max }$ is an important, though not the only, determinant of the IMT-mediated increase in $P_{\mathrm{I}, \max }$ and that great care must therefore be taken in standardising $P_{\mathrm{I}, \max }$ when recruiting participants for IMT-based interventions. The IMTmediated increases in $P_{\mathrm{di}}$ and $P_{\mathrm{oe}} / P_{\mathrm{di}}$ during the Müeller manoeuvre indicates that all inspiratory muscles are targeted by IMT. Furthermore, the increase in $P_{\mathrm{di}}$ at RV during the Müeller manoeuvre may have been permitted due to greater recruitment of the inspiratory chest wall muscles after IMT. Whether IMT-mediated increases in $P_{\mathrm{oe}} / P_{\mathrm{di}}$ reflect a greater relative training load placed on the inspiratory chest wall muscles or a shift in recruitment strategy remains unknown. 


\section{References}

ATS/ERS, 2002. ATS/ERS Statement on respiratory muscle testing. Am J Respir Crit Care Med 166, 518-624.

ATS/ERS, 2005. Standardization of spirometry: ATS/ERS Task Force. 2005;26:319-38. European Respiratory Journal 26, 319-338.

Baydur, A., Behrakis, P.K., Zin, W.A., Jaeger, M., Milic-Emili, J., 1982. A simple method for assessing the validity of the esophageal balloon technique. Am Rev Respir Dis 126, 788791.

Brown, P.I., Sharpe, G.R., Johnson, M.A., 2008. Inspiratory muscle training reduces blood lactate concentration during volitional hyperpnoea. Eur J Appl Physiol 104, 111-117.

Brown, P.I., Sharpe, G.R., Johnson, M.A., 2010. Loading of trained inspiratory muscles speeds lactate recovery kinetics. Med Sci Sports Exerc 42, 1103-1112.

Brown, P.I., Sharpe, G.R., Johnson, M.A., 2012. Inspiratory muscle training abolishes the blood lactate increase associated with volitional hyperpnoea superimposed on exercise and accelerates lactate and oxygen uptake kinetics at the onset of exercise. Eur J Appl Physiol $112,2117-2129$.

De Troyer, A., Kirkwood, P.A., Wilson, T.A., 2005. Respiratory action of the intercostal muscles. Physiol Rev 85, 717-756.

Downey, A.E., Chenoweth, L.M., Townsend, D.K., Ranum, J.D., Ferguson, C.S., Harms, C.A., 2007. Effects of inspiratory muscle training on exercise responses in normoxia and hypoxia. Respir Physiol Neurobiol 156, 137-146.

Eastwood, P.R., Hillman, D.R., Morton, A.R., Finucane, K.E., 1998. The effects of learning on the ventilatory responses to inspiratory threshold loading. Am J Respir Crit Care Med 158, 1190-1196.

Enright, S.J., Unnithan, V.B., Heward, C., Withnall, L., Davies, D.H., 2006. Effect of highintensity inspiratory muscle training on lung volumes, diaphragm thickness, and exercise capacity in subjects who are healthy. Phys Ther 86, 345-354.

Gandevia, S.C., McKenzie, D.K., Plassman, B.L., 1990. Activation of human respiratory muscles during different voluntary manoeuvres. J Physiol 428, 387-403.

Häkkinen, K., 1994. Neuromuscular adaptation during strength training, aging, detraining and immobilization. Critical Reviews in Physical and Rehabilitation Medicine 63, 161-198.

Hart, N., Sylvester, K., Ward, S., Cramer, D., Moxham, J., Polkey, M.I., 2001. Evaluation of an inspiratory muscle trainer in healthy humans. Respir Med 95, 526-531.

Hershenson, M.B., Kikuchi, Y., Loring, S.H., 1988. Relative strengths of the chest wall muscles. J Appl Physiol 65, 852-862. 
Hershenson, M.B., Kikuchi, Y., Tzelepis, G.E., McCool, F.D., 1989. Preferential fatigue of the rib cage muscles during inspiratory resistive loaded ventilation. J Appl Physiol (1985) 66, $750-754$.

Illi, S.K., Held, U., Frank, I., Spengler, C.M., 2013. Effect of respiratory muscle training on exercise performance in healthy individuals: a systematic review and meta-analysis. Sports Med 42, 707-724.

Johnson, M.A., Sharpe, G.R., Brown, P.I., 2007. Inspiratory muscle training improves cycling time-trial performance and anaerobic work capacity but not critical power. Eur J Appl Physiol 101, 761-770.

Johnson, P.H., Cowley, A.J., Kinnear, W.J., 1996. Evaluation of the THRESHOLD trainer for inspiratory muscle endurance training: comparison with the weighted plunger method. Eur Respir J 9, 2681-2684.

Johnson, P.H., Cowley, A.J., Kinnear, W.J., 1997. Incremental threshold loading: a standard protocol and establishment of a reference range in naive normal subjects. Eur Respir J 10, $2868-2871$.

Kenyon, C.M., Cala, S.J., Yan, S., Aliverti, A., Scano, G., Duranti, R., Pedotti, A., Macklem, P.T., 1997. Rib cage mechanics during quiet breathing and exercise in humans. J Appl Physiol 83, 1242-1255.

Kraemer, W.J., Fleck, S.J., Evans, W.J., 1996. Strength and power training: physiological mechanisms of adaptation. Exerc Sport Sci Rev 24, 363-397.

Larson, J.L., Covey, M.K., Vitalo, C.A., Alex, C.G., Patel, M., Kim, M.J., 1993. Maximal inspiratory pressure. Learning effect and test-retest reliability in patients with chronic obstructive pulmonary disease. Chest 104, 448-453.

Leith, D.E., Bradley, M., 1976. Ventilatory muscle strength and endurance training. J Appl Physiol 41, 508-516.

McConnell, A.K., Romer, L.M., Volianitis, S., Donovan, K.J., 2002. Re: Evaluation of an inspiratory muscle trainer in healthy humans (Respir Med 2001; 95: 526-531). Respir Med 96, 129-133.

McKenzie, D.K., Allen, G.M., Gandevia, S.C., 1996. Reduced voluntary drive to the human diaphragm at low lung volumes. Respir Physiol 105, 69-76.

Milic-Emili, J., Mead, J., Turner, J.M., Glauser, E.M., 1964. Improved Technique for Estimating Pleural Pressure from Esophageal Balloons. J Appl Physiol 19, 207-211.

Nava, S., Ambrosino, N., Crotti, P., Fracchia, C., Rampulla, C., 1993. Recruitment of some respiratory muscles during three maximal inspiratory manoeuvres. Thorax 48, 702-707.

Polkey, M.I., Moxham, J., Green, M., 2011. The case against inspiratory muscle training in COPD. Against. Eur Respir J 37, 236-237.

Ramirez-Sarmiento, A., Orozco-Levi, M., Guell, R., Barreiro, E., Hernandez, N., Mota, S., Sangenis, M., Broquetas, J.M., Casan, P., Gea, J., 2002. Inspiratory muscle training in 
patients with chronic obstructive pulmonary disease: structural adaptation and physiologic outcomes. Am J Respir Crit Care Med 166, 1491-1497.

Romer, L.M., McConnell, A.K., 2004. Inter-test reliability for non-invasive measures of respiratory muscle function in healthy humans. Eur J Appl Physiol 91, 167-176.

Romer, L.M., McConnell, A.K., Jones, D.A., 2002a. Effects of inspiratory muscle training on time-trial performance in trained cyclists. J Sports Sci 20, 547-562.

Romer, L.M., McConnell, A.K., Jones, D.A., 2002b. Inspiratory muscle fatigue in trained cyclists: effects of inspiratory muscle training. Med Sci Sports Exerc 34, 785-792.

Romer, L.M., Miller, J.D., Haverkamp, H.C., Pegelow, D.F., Dempsey, J.A., 2007. Inspiratory muscles do not limit maximal incremental exercise performance in healthy subjects. Respir Physiol Neurobiol 156, 353-361.

Roussos, C., Fixley, M., Gross, D., Macklem, P.T., 1979. Fatigue of inspiratory muscles and their synergic behavior. J Appl Physiol Respir Environ Exerc Physiol 46, 897-904.

Volianitis, S., McConnell, A.K., Jones, D.A., 2001a. Assessment of maximum inspiratory pressure. Prior submaximal respiratory muscle activity ('warm-up') enhances maximum inspiratory activity and attenuates the learning effect of repeated measurement. Respiration $68,22-27$.

Volianitis, S., McConnell, A.K., Koutedakis, Y., McNaughton, L., Backx, K., Jones, D.A., 2001b. Inspiratory muscle training improves rowing performance. Med Sci Sports Exerc 33, 803-809.

Wen, A.S., Woo, M.S., Keens, T.G., 1997. How many maneuvers are required to measure maximal inspiratory pressure accurately. Chest 111, 802-807.

Wilson, S.H., Cooke, N.T., Edwards, R.H., Spiro, S.G., 1984. Predicted normal values for maximal respiratory pressures in caucasian adults and children. Thorax 39, 535-538.

Winkler, G., Zifko, U., Nader, A., Frank, W., Zwick, H., Toifl, K., Wanke, T., 2000. Dosedependent effects of inspiratory muscle training in neuromuscular disorders. Muscle Nerve $23,1257-1260$. 
Table 1 Experiment 1: Inspiratory muscle strength, pulmonary function, dynamic inspiratory muscle function and inspiratory muscle endurance prior to (Baseline) and following the $4 \mathrm{wk}$ control period (Post-control/pre-IMT) and following $4 \mathrm{wk}$ inspiratory muscle training (PostIMT).

\begin{tabular}{|c|c|c|c|}
\hline & Baseline & $\begin{array}{l}\text { Post-Control / } \\
\text { pre-IMT }\end{array}$ & Post-IMT \\
\hline \multicolumn{4}{|c|}{ Maximal inspiratory pressure and pulmonary function } \\
\hline$P_{\mathrm{I}, \max }\left(\mathrm{cmH}_{2} \mathrm{O}\right)$ & $147 \pm 48$ & $149 \pm 45$ & $174 \pm 48 *$ \\
\hline $\mathrm{FVC}(\mathrm{L})$ & $4.67 \pm 0.86$ & $4.68 \pm 0.89$ & $4.70 \pm 0.89$ \\
\hline $\mathrm{FEV}_{1}(\mathrm{~L})$ & $3.89 \pm 0.69$ & $3.84 \pm 0.74$ & $3.84 \pm 0.74$ \\
\hline $\mathrm{FEV}_{1} / \mathrm{FVC}(\%)$ & $83.6 \pm 6.5$ & $82.3 \pm 6.9$ & $82.2 \pm 6.7$ \\
\hline $\operatorname{PEF}\left(\mathrm{L} \cdot \mathrm{s}^{-1}\right)$ & $8.39 \pm 1.76$ & $8.38 \pm 1.77$ & $8.46 \pm 1.87$ \\
\hline $\operatorname{MVV}_{10}\left(\mathrm{~L} \cdot \mathrm{min}^{-1}\right)$ & $152.5 \pm 36.3$ & $154.4 \pm 37.1$ & $158.7 \pm 38.4$ \\
\hline \multicolumn{4}{|c|}{ Dynamic inspiratory muscle function and inspiratory muscle endurance } \\
\hline$P_{0}\left(\mathrm{cmH}_{2} \mathrm{O}\right)$ & $143 \pm 41$ & $150 \pm 43$ & $172 \pm 49 *$ \\
\hline$\dot{\mathrm{V}}_{\mathrm{I}} \max \left(\mathrm{L} \cdot \mathrm{s}^{-1}\right)$ & $7.26 \pm 1.44$ & $7.16 \pm 1.43$ & $7.55 \pm 1.35^{*}$ \\
\hline$\dot{\mathrm{W}}_{\mathrm{I}} \max \left(\mathrm{cmH}_{2} \mathrm{O} \cdot \mathrm{L}^{-1} \cdot \mathrm{s}^{-1}\right)$ & $246.7 \pm 94.8$ & $244.1 \pm 89.4$ & $328.8 \pm 109.0^{*}$ \\
\hline$\dot{\mathrm{V}}_{\mathrm{opt}}\left(\mathrm{L} \cdot \mathrm{s}^{-1}\right)$ & $3.70 \pm 0.70$ & $3.64 \pm 0.73$ & $3.82 \pm 0.78 *$ \\
\hline$\dot{P}_{\mathrm{opt}}\left(\mathrm{cmH}_{2} \mathrm{O}\right)$ & $64.1 \pm 18.3$ & $66.5 \pm 16.5$ & $83.6 \pm 22.0 *$ \\
\hline$\% \dot{\mathrm{V}}_{\mathrm{I}} \max (\%)$ & $50.5 \pm 5.3$ & $50.9 \pm 3.6$ & $50.5 \pm 4.6$ \\
\hline$\% P_{0} \max (\%)$ & $44.9 \pm 7.0$ & $48.6 \pm 5.3$ & $49.2 \pm 6.1$ \\
\hline $\operatorname{MRPD}\left(\mathrm{cmH}_{2} \mathrm{O} \cdot \mathrm{ms}^{-1}\right)$ & $0.51 \pm 0.19$ & $0.47 \pm 0.17$ & $0.76 \pm 0.69 *$ \\
\hline ITL (min) & $13.58 \pm 4.98$ & $13.43 \pm 5.30$ & $16.03 \pm 4.76^{*}$ \\
\hline
\end{tabular}

Values are expressed as means \pm SD. $* P<0.05$ vs. post-control. For abbreviations see methodology, Experiment 1. 
Table 2 Experiment 2: Baseline inspiratory muscle strength and pulmonary function of the control and inspiratory muscle training (IMT) groups.

\begin{tabular}{lcc}
\hline & Control & IMT \\
\hline$P_{\mathrm{I}, \max } \mathrm{RV}\left(\mathrm{cmH}_{2} \mathrm{O}\right)$ & $155 \pm 44$ & $170 \pm 50$ \\
$P_{\mathrm{I}, \max } \mathrm{FRC}\left(\mathrm{cmH}_{2} \mathrm{O}\right)$ & $148 \pm 408$ & $137 \pm 30$ \\
$\mathrm{FVC}(\mathrm{L})$ & $5.43 \pm 0.92$ & $4.92 \pm 0.66$ \\
$\mathrm{FEV}_{1}(\mathrm{~L})$ & $4.22 \pm 0.78$ & $3.92 \pm 0.77$ \\
$\mathrm{FEV}_{1} / \mathrm{FVC}(\%)$ & $79.3 \pm 6.4$ \\
$\mathrm{PEF}\left(\mathrm{L} \cdot \mathrm{s}^{-1}\right)$ & $10.04 \pm 1.81$ & $8.43 \pm 1.64$ \\
$\mathrm{MVV}_{10}\left(\mathrm{~L} \cdot \mathrm{min}^{-1}\right)$ & $186.1 \pm 36.4$ & $172.4 \pm 41.0$ \\
\hline
\end{tabular}

$* P<0.05$ between groups. For abbreviations see methodology, Experiment 1 . 
Table 3 Experiment 2: Intrathoracic pressures during a Müeller manoeuvre in the control and IMT groups prior to and following the intervention period.

RV pre $\quad$ RV post $\quad$ FRC pre $\quad$ FRC post

\section{Control Group}

$\begin{array}{lcccc}P_{\mathrm{oe}}\left(\mathrm{cmH}_{2} \mathrm{O}\right) & -129.3 \pm 46.0 & -129.7 \pm 52.3 & -132.0 \pm 36.4 & -133.2 \pm 39.2 \\ P_{\mathrm{ga}}\left(\mathrm{cmH}_{2} \mathrm{O}\right) & 20.8 \pm 24.8 & 23.8 \pm 23.6 & 29.7 \pm 22.0 & 27.6 \pm 18.5 \\ P_{\mathrm{di}}\left(\mathrm{cmH}_{2} \mathrm{O}\right) & 150.0 \pm 40.8 & 153.6 \pm 36.9 & 161.8 \pm 41.8 & 160.8 \pm 43.8 \\ P_{\mathrm{oe}} / P_{\mathrm{di}}(\%) & 85.2 \pm 85.1 & 84.8 \pm 18.2 & 82.2 \pm 13.3 & 83.4 \pm 11.8\end{array}$

\section{IMT Group}

$$
\begin{array}{ccccc}
P_{\mathrm{oe}}\left(\mathrm{cmH}_{2} \mathrm{O}\right) & -126.3 \pm 20.0 & -144.6 \pm 29.9 * * & -117.2 \pm 26.9 & -136.8 \pm 31.5 * * \\
P_{\mathrm{ga}}\left(\mathrm{cmH}_{2} \mathrm{O}\right) & 28.8 \pm 27.1 & 24.6 \pm 23.9 & 35.6 \pm 24.9 & 31.2 \pm 28.3 \\
P_{\mathrm{di}}\left(\mathrm{cmH}_{2} \mathrm{O}\right) & 152.1 \pm 32.7 & 166.7 \pm 39.9 * & 147.8 \pm 33.3 & 168.0 \pm 35.2 *
\end{array}
$$

\begin{tabular}{ccccc}
$P_{\mathrm{oe}} / P_{\mathrm{di}}(\%)$ & $84.4 \pm 10.1$ & $88.3 \pm 12.2 *$ & $80.4 \pm 14.0$ & $82.6 \pm 14.5 *$ \\
\hline$* P<0.05$ and $* * P<0.01$ vs. pre. $P_{\mathrm{oe}}=$ oesophageal pressure; $P_{\mathrm{ga}}=$ gastric pressure; $P_{\mathrm{di}}=$ transdiaphragmatic
\end{tabular} pressure. 


\section{Figure captions}

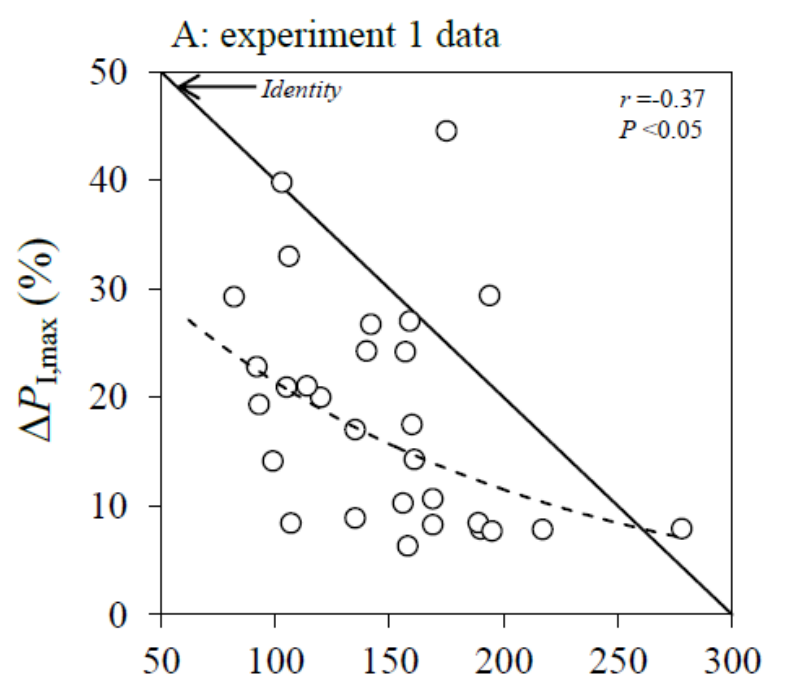

Baseline MIP $\left(\mathrm{cmH}_{2} \mathrm{O}\right)$

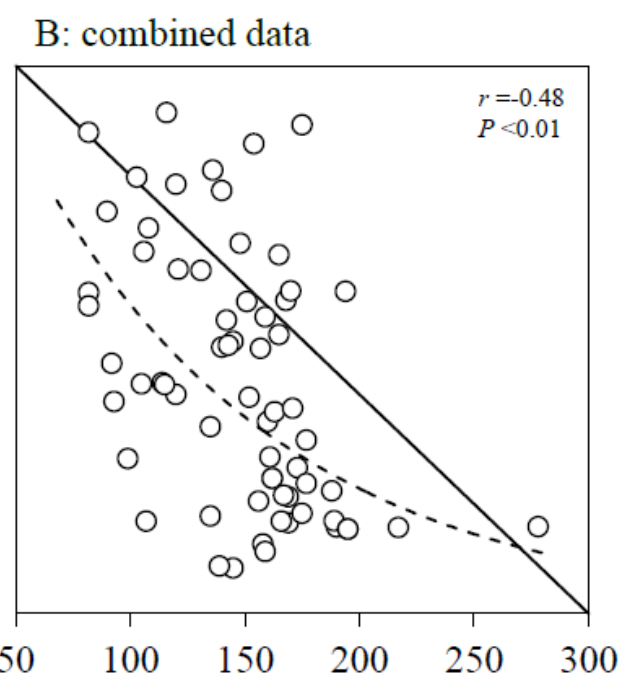

Baseline MIP $\left(\mathrm{cmH}_{2} \mathrm{O}\right)$

Figure 1 Relationship between baseline maximal inspiratory pressure (Baseline $P_{\mathrm{I}, \max }$ ) and the relative change in $P_{\mathrm{I}, \max }\left(\Delta P_{\mathrm{I}, \max }\right)$ following $4 \mathrm{wk}$ inspiratory muscle training with (A) data from Experiment 1 [ $\mathrm{n}=29]$ and $(\mathrm{B})$ data from Experiment 1 combined with data from our previous studies [ $n=67$ ] (Brown et al., 2008, 2010, 2012; Johnson et al., 2007). An exponential model fit was used in both (A) and (B). 